\title{
PENGARUH PENERAPAN STRATEGI THINK TALK WRITE TERHADAP HASIL BELAJAR SISWA PADA MATA PELAJARAN TEKNOLOGI INFORMASI DAN KOMUNKASI (TIK) DI KELAS X SMA N 1 LEMBAH GUMANTI
}

\author{
Rahmi Oktarina ${ }^{1}$, \\ Sekolah Tinggi Manajemen Informatika dan Komputer GICI \\ Email: rahmioktarina2016@gmail.com
}

\begin{abstract}
This research is motivated by the lack of interest, motivation and creativity of students, especially during theory lessons take place, such as the lack of a role in the learning process and the learning system is still dominated by the teacher. The method used in this study is quasy experiment. The population is class X SMA Negeri 1 Valley Gumanti totaling 207 people. The sampling technique used was purposive sampling. X4 grade students an experimental class and X6 grade students as a control group. The data collection technique is using achievement test, the data processed by t test (t-test). Based on the research results. The calculation result obtained $t$ t-test of 2.56, while the level of trust in 0:05 Ttable 2,000, so that $t>t$ table. Based on these data, it is known that there is a significant difference to the learning outcomes of students use learning strategies Think Talk Writedaripada using conventional learning strategies. Thus, it can be concluded that the application of learning strategies Think Talk Write affect student learning outcomes in class X SMA Negeri 1 Gumanti.
\end{abstract}

Keyword: Think Talk Write Strategy, Influence, Learning Outcomes.

\begin{abstract}
Abstrak
Penelitian ini dilatarbelakangi oleh rendahnya minat, motivasi dan kreatifitas siswa terutama saat pelajaran teori berlangsung, seperti kurangnya peran siswa dalam proses pembelajaran serta sistem pembelajaran yang masih didominasi oleh guru. Metode yang digunakan dalam penelitian ini adalah quasy experiment. Populasinya adalah siswa kelas X SMA NEGERI 1 Lembah Gumanti yang berjumlah 207 orang. Teknik penarikan sampel yang digunakan adalah purposive sampling. Siswa kelas $\mathrm{X}_{4}$ merupakan kelas eksperimen dan siswa kelas $\mathrm{X}_{6}$ sebagai kelas kontrol. Teknik pengumpulan data adalah menggunakan tes hasil belajar, data diolah dengan uji t (ttest). Berdasarkan hasil penelitian. Hasil perhitungan $t$-tes diperoleh $t_{\text {hitung }} 2,56$ sedangkan taraf kepercayaannya $0.05 t_{\text {tabel }} 2,000$, sehingga $t_{\text {hitung }}>t_{\text {tabel. }}$. Berdasarkan data tersebut, diketahui bahwa terdapat perbedaan yang signifikan terhadap hasil belajar siswa yang menggunakan strategi pembelajaran Think Talk Writedaripada menggunakan strategi pembelajaran konvensional. Dengan demikian, dapat disimpulkan bahwa penerapan strategi pembelajaran Think Talk Write mempengaruhi hasil belajar siswa kelas X SMA Negeri 1 Lembah Gumanti.
\end{abstract}

Kata Kunci: Strategi Think Talk Write, Pengaruh, Hasil Belajar

JURSIMA

Jurnal Sistem Informasi dan Manajemen https://ejournal.giciku.ac.id/ STMIK GICl 


\section{PENDAHULUAN}

Strategi belajar yang digunakan oleh pendidik berperan penting dalam meningkatkan hasil belajar siswa. Strategi belajar seharusnya tidak hanya mendukung materi yang sedang diajarkan, tetapi juga harus mendukung dan mengembangkan kemampuan belajar siswa.

Belajar adalah kegiatan yang berproses dan merupakan unsur yang sangat fundamental dalam penyelenggaraan dan setiap jenis pendidikan.(Muhibbin Syah, 2005:63). Belajar merupakan kegiatan yang kompleks, dan hasil belajar merupakan kapabilitas, timbulnya kapabilitas disebabkan: (1) stimulasi yang berasal dari lingkungan; dan (2) proses kognitif yang dilakukan oleh pelajar. Setelah belajar orang memiliki keterampilan, pengetahuan, sikap, dan nilai (Robert M. Gagne dalam Syaiful Sagala 2012:17). Pembelajaran merupakan proses komunikasi dua arah, mengajar dilakukan oleh pihak guru sebagai pendidik, sedangkan belajar dilakukan oleh peserta didik atau murid. (Syaiful Sagala 2012:61).

Berdasarkan uraian di atas dilakukan wawancara dengan salah satu guru Teknologi Informasi dan Komunikasi SMA N 1 Lembah Gumanti Kabupaten Solok. Sebagai hasilnya adalah diperoleh gambaran umum bahwa masalah belajar yang paling menonjol adalah kurangnya motivasi dan minat siswa dalam belajar terutama disaat pelajaran teori berlangsung.
Hal ini terlihat dengan adanya siswa yang keluar masuk di saat proses pembelajaran berlangsung. Selain itu, ketika guru meminta siswa untuk menjawab pertanyaan atau memeberikan tanggapan berkaitan materi pembelajaran hanya sebagian siswa yang berminat memberikan tanggapan. hal itu terjadi karena kurangnya pemahaman siswa tentang materi yang disampaikan oleh guru. Secara umum, metode pembelajaran yang digunakan oleh guru adalah metode ceramah. Pada metode ini, siswa tidak memiliki kesempatan yang cukup untuk dapat mengembangkan ide, pendapat, gagasan atau kemampuan lain yang mereka miliki sehingga siswa menjadi pasif dalam proses pembelajaran. Siswa menjadi kurang termotivasi serta merasa cepat bosan dalam mengikuti pembelajaran. Selain itu, mereka tidak terbiasa bekerja sama dengan baik dalam kelompok di dalam kelas. Hal ini menyebabkan interaksi antara siswa dengan siswa serta siswa dengan guru sangat minim sekali sehingga pembelajaran di kelas menjadi monoton. Pembelajaran diawali dengan menjelaskan materi. melakukan praktek dan diberi tugas soal latihan yang ada pada buku paket siswa, dilanjutkan dengan memberikan tugas pekerjaan rumah. Sehingga pada pembelajaran tersebut terlihat bahwa pembelajaran cenderung didominasi oleh guru. Selain dominasi guru, hal lain yang menyebabkan siswa menjadi pasif dalam proses pembelajaran adalah siswa malas membaca materi yang 
dalam tujuan pembelajaran. (Nana Sudjana 2002:35).

Dalam metode Think Talk Write, pembelajaran akan lebih efektif jika dilakukan dalam bentuk kelompok dengan anggota tiga sampai lima orang siswa setiap kelompok. Strategi Think Talk Write merupakan salah satu pembelajaran yang dimulai dengan keterlibatan siswa dalam berfikir (Think) atau berdialog dengan dirinya sendiri setelah membaca LKS yang diberikan. Lembar Kegiatan Siswa (student worksheet) adalah lembaran-lembaran berisi tugas yang harus dikerjakan oleh peserta didik. Lembaran itu biasanya berupa petunjuk, langkah-langkah untuk menyelesaikan suatu tugas. Penggunaan LKS sebagai alat bantu dalam belajar dapat memberikan keuntungan bagi guru dan siswa dalam pelaksanaan proses pembelajaran. Dengan menggunakan LKS siswa dapat belajar secara mandiri, memahami dan melaksanakan suatu tugas tertulis. Depdiknas (2008:13)

Kegiatan ini dapat dilihat dari proses siswa membaca dan membuat catatan dari apa yang telah dibacanya. Kegiatan ini dapat meningkatkan keterampilan berfikir siswa. Dengan fase ini, siswa bisa memiliki pemikiran serta pemahaman sendiri tentang materi. Setelah itu, mereka juga bisa mengemukakan pendapat mereka berkaitan dengan materi melalui tahapan Talk. Talk merupakan tahapan ketika siswa berbicara atau mengkomunikasikan hasil pemikirannya dalam diskusi dan 
berbagi (sharing) dengan kelompok sebelum menulis. Siswa menyampaikan hasil diskusinya dengan kelompok dalam bentuk presentasi singkat. Pembelajaran akan menjadi lebih efektif dengan melengkapi proses pembelajaran dengan tahapan Write. Dalam fase ini, siswa dalam kelompok diminta untuk membuat catatan kecil, menjelaskan, mendengarkan dan membagi ide bersama teman. Siswa menuliskan (write) kembali pengetahuan atau informasi apa saja yang didapat dari tahapan sebelumnya. Pada tahapan write siswa mengkonstruksi sendiri hasil tahapan think dan talk dalam bentuk ringkasan materi yang dibuat secara individu. (Martinis Yamin \& Bansu I. Ansari 2009:84)

Dari uraian di atas dapat dirumuskan bahwa permasalahannya adalah penggunaan strategi pembelajaran sangat berpengaruh terhadap hasil belajar siswa pada mata pelajaran Teknologi Informasi dan Komunikasi di SMA NEGERI 1 Lembah Gumanti Kab.Solok. Adapun tujuan yang ingin dicapai pada penelitian ini adalah mengetahui pengaruh penggunaan metode Think Talk Write (TTW) terhadap hasil belajar siswa pada mata pelajaran Teknologi Informasi dan Komunikasi Kelas X di SMA Negeri 1 Lembah Gumanti Kab. Solok.

\section{METODOLOGI}

Dalam Penelitian ini, peneliti menggunakan pendekatan kuantitatif dalam bentuk quasy experiment. Peneliti mencoba strategi pembelajaran Think Talk Write(variabel bebas) kepada siswa dan hasil belajar (variabel terikat) kepada siswa tersebut. Populasi pada peneltian ini adalah siswa yang terdiri dari dari 6 lokal, dengan jumlah siswa seluruhnya 207 oranng. Penelitian dilakukan terhadap seluruh siswa kelas $\mathrm{X}$ SMA N 1 Lembah Gumanti.

Dalam penelitian ini, teknik penarikan sampel yang digunakan adalah purposive sampling. Siswa kelas $\mathrm{X}_{4}$ merupakan kelas eksperimen dan siswa kelas $\mathrm{X}_{6}$ SMA NEGERI 1 Lembah Gumanti sebagai kelas kontrol dalam peneliatian ini.

Teknik pengumpulan data dalam penelitian ini menggunakan tes hasil belajar lembaran soal tes sebagai media pengumpul data. Data yang digunakan adalah data yang diperoleh dari hasil belajar siswa berdasarkan nilai test akhir sebanyak 40 soal objektif yang dilakukan setelah penelitian. Setelah itu, data diolah dengan uji t (t-test).

Teknik analisis data menggunakan perbedaan dua ratarata nilai dengan menggunakan uji t. Sebelum melakukan uji t, dilakukan uji Normalitas dan uji Homogenitas sampel.

\section{HASIL}

Data yang dideskripsikan dalam penelitian ini terdiri dari dua kelompok yaitu data tentang hasil belajar siswa yang diajarkan dengan menggunakan strategi pembelajaran Think Talk Write disebut dengan kelompok eksperimen dan data tentang hasil belajar siswa yang diajar dengan pembelajaran 
Volume 5 No. 1

Mei 2017

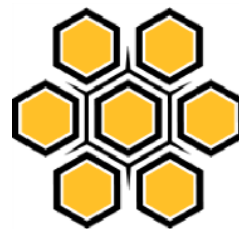

konvensional disebut dengan kelompok kontrol.

Tabel 1. Rangkuman Hasil Belajar TIK Siswa yang Menggunakan Strategi Think Talk Write dan Menggunakan Strategi Konvensional

\begin{tabular}{|c|c|c|}
\hline \multirow[b]{2}{*}{ Variabel } & \multicolumn{2}{|c|}{ Strategi Pembelajaran } \\
\hline & $\begin{array}{c}\text { Think } \\
\text { Talk } \\
\text { Write }\end{array}$ & Konvensional \\
\hline (1) & (2) & (3) \\
\hline Jumlah Siswa & 35 & 35 \\
\hline Skor Tertinggi & 90 & 85 \\
\hline Skor Terendah & 57,5 & 55 \\
\hline Jumlah Nilai & 2615 & 2435 \\
\hline Rata-rata & 74,71 & 69,57 \\
\hline SD & 8,35 & 8,21 \\
\hline $\mathrm{SD}^{2}$ & 69,77 & 67,46 \\
\hline
\end{tabular}

Jumlah siswa yang diajar dengan strategi pembelajaran Think Talk Write sejumlah 35 orang atau dalam satu kelas. Setelah diperoleh nilai hasil belajar, terlihat bahwa nilai tertinggi yang berhasil dicapai siswa adalah 90 dan nilai terendahnya adalah 57,5. Jumlah nilai keseluruhan untuk siswa yang berjumlah 35 orang adalah 2615 dengan nilai ratarata 74,71 dan standar deviasi 8,35. Keterangan lebih rinci hasil belajar yang menggunakan strategi Think Talk Write pada tabel di bawah ini:

Tabel 2.Frekuensi Data Nilai Hasil Belajar TIK Siswa Kelas Eksperimen

\begin{tabular}{|c|c|c|c|}
\hline Interval & $\begin{array}{c}\text { Titik } \\
\text { Tengah }\end{array}$ & $\mathbf{F}$ & $\mathbf{\%}$ \\
\hline $\mathbf{( 1 )}$ & $\mathbf{( 2 )}$ & $\mathbf{( 3 )}$ & $\mathbf{( 4 )}$ \\
\hline $56-60$ & 58 & 3 & 8,57 \\
\hline $61-65$ & 63 & 3 & 8,57 \\
\hline $66-70$ & 68 & 5 & 14,29 \\
\hline $71-75$ & 73 & 10 & 28,57 \\
\hline $76-80$ & 78 & 7 & 20,0 \\
\hline & & & \\
& & & \\
\hline $81-85$ & 83 & 4 & 11,43 \\
\hline $86-90$ & 88 & 3 & 8,57 \\
\hline Jumlah & & 35 & 100,0 \\
\hline
\end{tabular}

JURSIMA

Jurnal Sistem Informasi dan Manajemen
Data hasil belajar siswa yang diperoleh dari kelas $\mathrm{X}_{6} \quad$ (Kelas Kontrol) dengan menggunakan model konvensional yaitu berjumlah 35 orang. Untuk lebih lengkapnya Interval skor data nilai hasil belajar TIK kelas kontrol dapat dilihat pada tabel :

Tabel 3. Frekuensi Data Nilai Hasil Belajar TIK Siswa Kelas Kontrol

\begin{tabular}{|c|c|c|c|}
\hline Interval & $\begin{array}{c}\text { Titik } \\
\text { Tengah }\end{array}$ & $\mathbf{f}$ & \% \\
\hline $\mathbf{( 1 )}$ & $\mathbf{( 2 )}$ & $\mathbf{( 3 )}$ & $\mathbf{( 4 )}$ \\
\hline $51-55$ & 53 & 1 & 2,86 \\
\hline $56-60$ & 58 & 4 & 11,43 \\
\hline $61-65$ & 63 & 9 & 25,71 \\
\hline $66-70$ & 68 & 7 & 20,0 \\
\hline $71-75$ & 73 & 5 & 14,29 \\
\hline $76-80$ & 78 & 5 & 14,29 \\
\hline $81-85$ & 83 & 4 & 11,43 \\
\hline Jumlah & & $\mathbf{3 5}$ & $\mathbf{1 0 0 , 0}$ \\
\hline
\end{tabular}

Data tes akhir kelas eksperimen dan kelas kontrol diolah untuk menentukan uji normalitas. Pada uji normalitas ini digunakan uji Liliefors seperti yang dikemukakan pada teknik analisis data. Analisis normalitas pada kelas eksperimen dan kelas kontrol terdapat pada lampiran dan halaman. Berdasarkan uji normalitas kelas eksperimen dan kelas kontrol diperoleh harga $\mathrm{L}_{0}$ dan $\mathrm{L}_{\mathrm{t}}$ pada taraf nyata 0,05 untuk $\mathrm{n}>30$ seperti pada tabel :

Tabel 4.Hasil perhitungan Pengujian Lilifors Kelompok Eksperimen dan Kelompok Kontrol

\begin{tabular}{|l|l|l|l|l|l|l|}
\hline $\begin{array}{l}\mathbf{N} \\
\mathbf{o}\end{array}$ & $\begin{array}{l}\text { Kela } \\
\mathbf{S}\end{array}$ & $\mathbf{N}$ & $\mathbf{A}$ & $\mathbf{L}_{\mathbf{0}}$ & $\mathbf{L}_{\mathbf{t}}$ & $\begin{array}{l}\text { Ketera } \\
\text { ngan }\end{array}$ \\
\hline 1 & $\begin{array}{l}\text { Ekspe } \\
\text { rimen }\end{array}$ & 35 & $\begin{array}{l}0,0 \\
5\end{array}$ & $\begin{array}{l}0,08 \\
80\end{array}$ & $\begin{array}{l}0,1 \\
50\end{array}$ & Normal \\
\hline 2 & $\begin{array}{l}\text { Kontr } \\
\text { ol }\end{array}$ & 35 & $\begin{array}{l}0,0 \\
5\end{array}$ & $\begin{array}{l}0,11 \\
29\end{array}$ & $\begin{array}{l}0,1 \\
50\end{array}$ & Normal \\
\hline
\end{tabular}

https://ejournal.giciku.ac.id/ STMIK GICI 


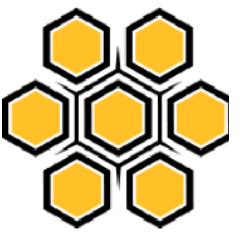

Dari Tabel perhitungan uji Liliefors terlihat bahwa kelas eksperimen nilai $L$ hitung 0,0880 lebih kecil dari $L$ table 0,150 untuk $\alpha 0,05$. Dengan demikian nilai kelompok eksperimen berasal dari data yang berdistribusi normal. Untuk kelas kontrol diperoleh $L$ hitung 0,1129 lebih kecil dari $L$ tabel 0,150 untuk $\alpha 0,05$. Ini terlihat bahwa data kelompok kontrol berasal dari data yang berdistribusi normal.

Setelah uji normalitas, selanjutnya dilaksanakan uji homogenitas yang bertujuan untuk mengetahui apakah data sampel mempunyai varians yang homogen. Penghitungan Homogenitas (Uji Barlet) dapat di lihat pada lampiran halaman . Hasil perhitungan dapat dilihat pada tabel .

Tabel 5.Hasil Uji Homogenitas Kelas Eksperimen dan Kelas Kontrol

\begin{tabular}{|l|l|l|l|l|}
\hline Kelas & A & $\chi^{2}$ & $\chi^{2}$ & Kesimpulan \\
hitung & tabel & \\
\hline Eksperimen & 0,05 & 0,78 & 3,841 & Homogen \\
\cline { 1 - 3 } Kontrol & & & & \\
\hline
\end{tabular}

Dari tabel uji homogenitas tampak bahwa $\chi^{2}$ hitung kelas eksperimen dan kelas kontrol lebih kecil dari $\chi_{\text {tabel }}^{2}$ ( $\chi_{\text {hitung }}^{2}<\chi_{\text {tabel }), \quad \text { berarti kelas }}^{2}$ eksperimen dan kelas kontrol memiliki varians yang homogen.

Untuk menguji hipotesis digunakan t-test. Dari hasil uji hipotesis dengan menggunakan t-test diperoleh hasil sebagai berikut:
Tabel 6. Hasil Pengujian dengan t-test

\begin{tabular}{|c|c|c|c|c|}
\hline $\begin{array}{l}\mathbf{N} \\
\mathbf{0}\end{array}$ & $\begin{array}{c}\text { Kelompok } \\
\text { / Hasil }\end{array}$ & $\begin{array}{c}\text { Nilai } \\
\text { Rata } \\
\text {-rata } \\
\text { Kela } \\
\text { S }\end{array}$ & $\begin{array}{c}\mathrm{t} \\
\text { hitun } \\
\mathrm{g}\end{array}$ & $\begin{array}{c}\mathrm{t} \\
\text { table } \\
\alpha \\
0,05\end{array}$ \\
\hline & (1) & (2) & (3) & (4) \\
\hline 1 & $\begin{array}{c}\text { Eksperime } \\
n\end{array}$ & 74,71 & \multirow[t]{2}{*}{2,56} & \multirow[t]{2}{*}{$\begin{array}{c}2,00 \\
0\end{array}$} \\
\hline 2 & Kontrol & 69,57 & & \\
\hline
\end{tabular}

Dilihat pada tabel $\mathrm{t}$ dengan $\mathrm{dk}$ $\left(\mathrm{N}_{1}-1\right)+\left(\mathrm{N}_{2}-1\right)=68$. Maka yang dipedomani pada tabel yaitu dengan df 68 untuk taraf nyata 0,05 didapat harga $t_{\text {tabel }} 2,000$. Dengan demikian $t$ hitung $>t_{\text {tabel }}$, yaitu 2,56>2,000 maka dapat dikatakan bahwa hipotesis $\mathrm{H} 1$ diterima yaitu terdapat perbedaan yang signifikan dari hasil belajar siswa antara kelas eksperimen yang menerapkan strategi pembelajaran Think Talk Writedibandingkan dengan kelas kontrol yang menggunakan strategi pembelajaran konvensional.

\section{PEMBAHASAN}

Berdasarkan hasil tes siswa berupa lembar soal objektif yang diberikan pada kelas $\mathrm{X}_{4}$ sebagai kelas eksperimen dan kelas $\mathrm{X}_{6}$ sebagai kelas kontrol diperoleh nilai rata-rata kelas eksperimen yang menggunakan strategi pembelajaran Think Talk Write yaitu 74,71 dan nilai rata-rata hasil belajar kelas kontrol yang menggunakan strategi pembelajaran konvensional yaitu 69,57.

Hasil analisis data yang telah dilakukan pada pengujian homogenitas data dari kedua kelompok diperoleh hasil $\chi_{\text {hitung }}^{2}$

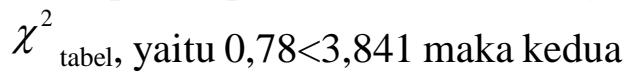

JURSIMA

Jurnal Sistem Informasi dan Manajemen https://ejournal.giciku.ac.id/ STMIK GICI 
kelompok memiliki varians yang homogen untuk $\alpha 0,05$. Sedangkan, pada pengujian hipotesis dengan menggunakan t-test diperoleh hasil t hitung $>\mathrm{t}$ tabel untuk $\alpha 0,05$ yaitu 2,56> 2,000 .

Hasil hipotesis menunjukkan bahwa hasil belajar siswa pada mata pelajaran Teknologi Informasi dan Komunikasi (TIK) di kelas X SMA NEGERI 1 Lembah Gumanti Kabupaten Solok yang mengikuti pembelajaran dengan menggunakan strategi pembelajaran Think Talk Write lebih tinggi dari hasil belajar siswa yang mengikuti pembelajaran konvensional, dan terdapat perbedaan yang signifikan dari hasil belajar siswa antara kelas eksperimen yang menggunakan strategi pembelajaran Think Talk Write pada mata pelajaran Teknologi Informasi dan Komunikasi (TIK) di kelas $\mathrm{X}$ SMA Negeri 1 Lembah Gumanti Kabupaten Solok dibandingkan dengan kelas kontrol yang menggunakan strategi pembelajaran konvensional.

Hal ini disebabkan bahwa strategi pembelajaran Think Talk Write mempunyai banyak keunggulan dibandingkan strategi pembelajaran konvensional. Karena strategi pembelajaran Think Talk Write memberikan kesempatan kepada siswa untuk mengkonstruksi pengetahuannya sendiri, siswa juga dituntut untuk mampu berfikir kritis dan menuliskan beberapa kesimpulan dan pendapat berdasarkan materi yang telah dibaca sehingga siswa lebih mudah untuk memahami materi pembelajaran.
Berdasarkan hal di atas terlihat jelas adanya perbedaan strategi serta metode mengajar antara kelas eksperimen dan kelas kontrol, yaitu pengaruh pada interaksi (partisipasi) dan hasil belajar siswa di kelas. Dengan kata lain, guru sebaiknya menerapkan strategi pembelajaran Think Talk Write, karena strategi pembelajaran ini dapat mempengaruhi faktor-faktor belajar seperti faktor intern yang mencakup faktor siswa berupa kesehatan dan kemampuan intelegensi siswa dan faktor ektern yang mencakup faktor sekolah. Hal ini sesuai dengan pendapat Slameto (2010:54) yaitu faktor jasmaniah dimana siswa dalam keadaan baik dapat mengikuti proses pembelajaran,faktor psikologis yang meliputi intelegensi, perhatian, minat, bakat, kematangan dan kesiapan. Faktor sekolah yang mempengaruhi belajar mencakup metode mengajar, kurikulum, relasi guru dengan siswa, relasi siswa dengan siswa, disiplin sekolah, pelajaran dan waktu sekolah, standar pelajaran, keadaan gedung, metode belajar dan tugas rumah.

\section{SIMPULAN DAN SARAN}

Pembelajaran dengan menerapkan strategi pembelajaran Think Talk Writememberi pengaruh yang signifikan terhadap hasil belajar siswa pada mata pelajaran TIK kelas $X$ SMA NEGERI 1 Lembah Gumanti. Hal ini membuktikan bahwa dengan menggunakan strategi pembelajaran Think Talk Writedapat meningkatkan hasil belajar siswa, Nilai rata-rata hasil belajar kelas 
eksperimen yaitu 74,71 dan nilai rata-rata hasil belajar kelas kontrol yang menggunakan strategi pembelajaran konvensional yaitu 69,57 yang berarti hasil belajar siswa kelas eksperimen lebih tinggi dari hasil belajar siswa kelas kontrol. Dari hasil uji hipotesis didapat bahwa $t_{\text {hitung }}>\mathrm{t}_{\text {tebel }}$ yaitu $(2,56>2,00)$ pada taraf signifikan $\alpha 0,05$ yang berarti terdapat perbedaan yang signifikan antara hasil belajar siswa yang menerapkan strategi pembelajaran Think Talk Write dengan hasil belajar yang menggunakan strategi pembelajaran konvensional. Dengan demikian penggunaan strategi pembelajaran Think Talk Writeberpengaruh terhadap hasil belajar siswa pada mata pelajaran TIK di SMA N 1 Lembah Gumanti. Setelah memperhatikan hasil penelitian dan kesimpulan diatas, maka peneliti ingin mengemukakan beberapa saran diantaranya, diharapkan pada guru mata pelajaran Teknologi Informasi dan Komunikasi hendaknya menggunakan strategi pembelajaran Think Talk Write yang dapat membuat siswa aktif dan termotivasi dalam proses pembelajaran, salah satunya dengan menggunakan strategi pembelajaran Think Talk Write.Kepada Kepala Sekolah SMA N 1 Lembah Gumanti Kab. Solok, pengawas maupun kepada tenaga kependidikan yang terkait dan bertanggung jawab terhadap keberhasilan pembelajaran TIK disekolah agar dapat memotivasi dan membina guru-guru agar menggunakan strategi pembelajaran Think Talk Write dalam proses pembelajaran untuk meningkatkan mutu pendidikan dimasa yang akan datang. Untuk penerapan strategi pembelajaran Think Talk Write sebaiknya tidak hanya dilakukan pada mata pelajaran Teknologi Informasi dan Komunikasi saja. Tetapi dapat juga digunakan pada mata pelajaran yang lain agar dapat meningkatkan kemampuan siswa dalam semua mata pelajaran di sekolah.

\section{DAFTAR RUJUKAN}

Ansari, Bansu I dan Martinus Yamin.2009. Taktik

Mengembangkan Kemampuan Individual Siswa. Jakarta: Gaung Persada Press.

Dimyati dan Mudjiono. 2009. Belajar dan Pembelajaran. Jakarta: Rineka Cipta.

Muhibbin Syah. 2005. Psikologi Belajar. Jakarta: Raja Grafindo Persada

Nana Sudjana. 2002. Dasar-dasar Proses Belajar Mengajar. Bandung: Sinar Baru Algensido.

Subana dkk.2005.Statistik Pendidikan. Bandung: Pustaka Setia

Suharsimi Arikunto. 1998. Prosedur Penelitian Suatu Pendekatan Praktek. Jakarta: Rineka Cipta.

Slameto. 2010. Belajar \& FaktorFaktor yang Mempengaruhinya. Jakarta: Rineka Cipta. 
ISSN 2338-1523

E-ISSN 2541-576X

Volume 5 No. 1

Mei 2017

Sulistyo Basuki. 1998. Dasar-dasar

Teknologi Informasi. Jakarta:

Universitas Terbuka

Syaiful Sagala. 2012. Konsep dan Makna Pembelajaran. Bandung: Alfabeta

Syafril. 2010. Statistika. Padang:

Sukabina Press 